\title{
Monitoring of corrosion damage using high-frequency guided ultrasonic waves
}

\author{
D. Chew and P. Fromme \\ Department of Mechanical Engineering, University College London, WC1E 7JE, UK
}

\begin{abstract}
Due to adverse environmental conditions corrosion can develop during the life cycle of industrial structures, e.g., offshore oil platforms, ships, and desalination plants. Both pitting corrosion and generalized corrosion leading to wall thickness loss can cause the degradation of the integrity and load bearing capacity of the structure. Structural health monitoring of corrosion damage in difficult to access areas can in principle be achieved using high frequency guided waves propagating along the structure from accessible areas. Using standard ultrasonic transducers with single sided access to the structure, high frequency guided wave modes were generated that penetrate through the complete thickness of the structure. Wall thickness reduction was induced using accelerated corrosion in a salt water bath. The corrosion damage was monitored based on the effect on the wave propagation and interference of the different modes. The change in the wave interference was quantified based on an analysis in the frequency domain (Fourier transform) and was found to match well with theoretical predictions for the wall thickness loss. High frequency guided waves have the potential for corrosion damage monitoring at critical and difficult to access locations from a stand-off distance.
\end{abstract}

Keywords: Corrosion Detection, High Frequency Guided Waves, Wall Thickness Loss, Monitoring

\section{INTRODUCTION}

Corrosion is one of the limiting factors for the service life of ships and offshore structures due to the corrosive marine environment leading to thickness reduction in metallic structures $[1,2]$. It is therefore essential that these structures are monitored nondestructively to predict and hence prevent failure. Corrosion occurs in several different forms, with either pitting corrosion or generalized thickness reduction due to 'uniform' corrosion as common types prevalent in ship hulls [1]. Pitting corrosion is difficult to detect as it is typically localized. Ultrasonic methods have been shown to have good sensitivity to small changes in thickness and both surface and subsurface flaws. In recent years, advances have been made in the development of low frequency guided ultrasonic wave inspection systems for the monitoring of large technical structures, e.g., offshore oil platforms, oil storage tanks, or pipelines [3, 4]. Such structures are often constructed using large plate-like components and are subject to corrosion and fatigue damage during their service life $[5,6]$. Efficient monitoring of the structural integrity of large areas of such structures from a single monitoring location can be achieved using a guided ultrasonic wave array system [7, 8]. Guided waves have stress distributed through the thickness of the structure and can propagate over large distances. At structural defects, e.g., severe thickness reduction due to corrosion pitting, the guided wave mode is scattered and part of its energy reflected back towards the monitoring location. This allows in principle for the efficient nondestructive testing and monitoring of large technical structures [9]. Guided wave monitoring systems usually operate at low frequencies below the cut-off frequencies for higher order wave modes to generate only the fundamental $\left(\mathrm{A}_{0}\right.$ or $\left.\mathrm{S}_{0}\right)$ wave modes, simplifying signal interpretation. The low frequency operating range necessitates larger wavelengths and thus limited sensitivity to small defects.

The application of guided ultrasonic wave modes in the higher frequency-thickness range has been investigated for nondestructive testing purposes [10]. The $\mathrm{S}_{0}$ mode (around $5 \mathrm{MHz} \mathrm{mm}$ ) was used for corrosion detection in aircraft structures [11], and longitudinal modes (above $15 \mathrm{MHz} \mathrm{mm}$ ) were employed for plate inspection [12]. This type of ultrasonic waves allows for the inspection of structures over reasonably long distances, and can be employed even if local access to the inspected part is not possible. The employed wavelengths are comparable to those commonly used in

Health Monitoring of Structural and Biological Systems 2014, edited by Tribikram Kundu, Proc. of SPIE Vol. 9064, 90642F .

(c) 2014 SPIE · CCC code: 0277-786X/14/\$18 · doi: 10.1117/12.2046301 
bulk wave ultrasonic testing (UT), possibly allowing good sensitivity for the detection of small defects [12]. The use of high frequency guided waves (coupled Rayleigh-like waves) at around $6.75 \mathrm{MHz} \mathrm{mm}$ has been studied for the detection and localization of surface defects in plates [13]. This wave type can be interpreted as the superposition of the first antisymmetric $\mathrm{A}_{0}$ and symmetric $\mathrm{S}_{0}$ Lamb wave modes [14]. These high frequency guided wave modes in plates are easily generated and received selectively above the cut-off frequencies of the higher Lamb wave modes using standard Rayleigh wave angle beam transducers. Standard pulse-echo measurements using a Rayleigh angle wedge transducer have been shown to allow for the detection of small surface defects in plates. Using a combination of time-of-flight and frequency evaluation of the reflected pulse, the defect location and damaged plate side could be determined [15]. Rayleigh-like waves were also used for in-situ monitoring of fatigue crack growth in tensile, aluminum specimens [16].

In the frequency range of interest for this investigation (around $5 \mathrm{MHz} \mathrm{mm}$ ), there is a slight difference between the phase velocities of the first anti-symmetric $\left(\mathrm{A}_{0}\right)$ and symmetric $\left(\mathrm{S}_{0}\right)$ Lamb wave modes. Therefore, during propagation there is a continual shift in relative phase, causing the transfer of the wave energy between the plate sides. The significant distance for this energy exchange, the so-called beatlength [17] or beat wavelength [18], is given by

$$
L=\frac{2 \pi}{k_{A 0}-k_{S 0}},
$$

with $k_{A 0}$ and $k_{S 0}$ the wavenumbers of $\mathrm{A}_{0}$ and $\mathrm{S}_{0}$, respectively. This interference depends strongly on both the frequency and thickness of the structure, as it is governed by the inverse of the difference between the phase velocities of the two fundamental Lamb wave modes. This effect has been investigated in this study to monitor the thickness reduction due to generalized corrosion in steel specimens. The concept was in a first step demonstrated by monitoring the thickness reduction for milled, uniform thickness specimens to develop reference measurements and gain an understanding of the sensitivity of the methodology [2]. During accelerated corrosion of a steel plate specimen the thickness reduction was monitored using longitudinal and high frequency guided ultrasonic waves to verify the applicability during actual corrosion leading to thicknesses reduction.

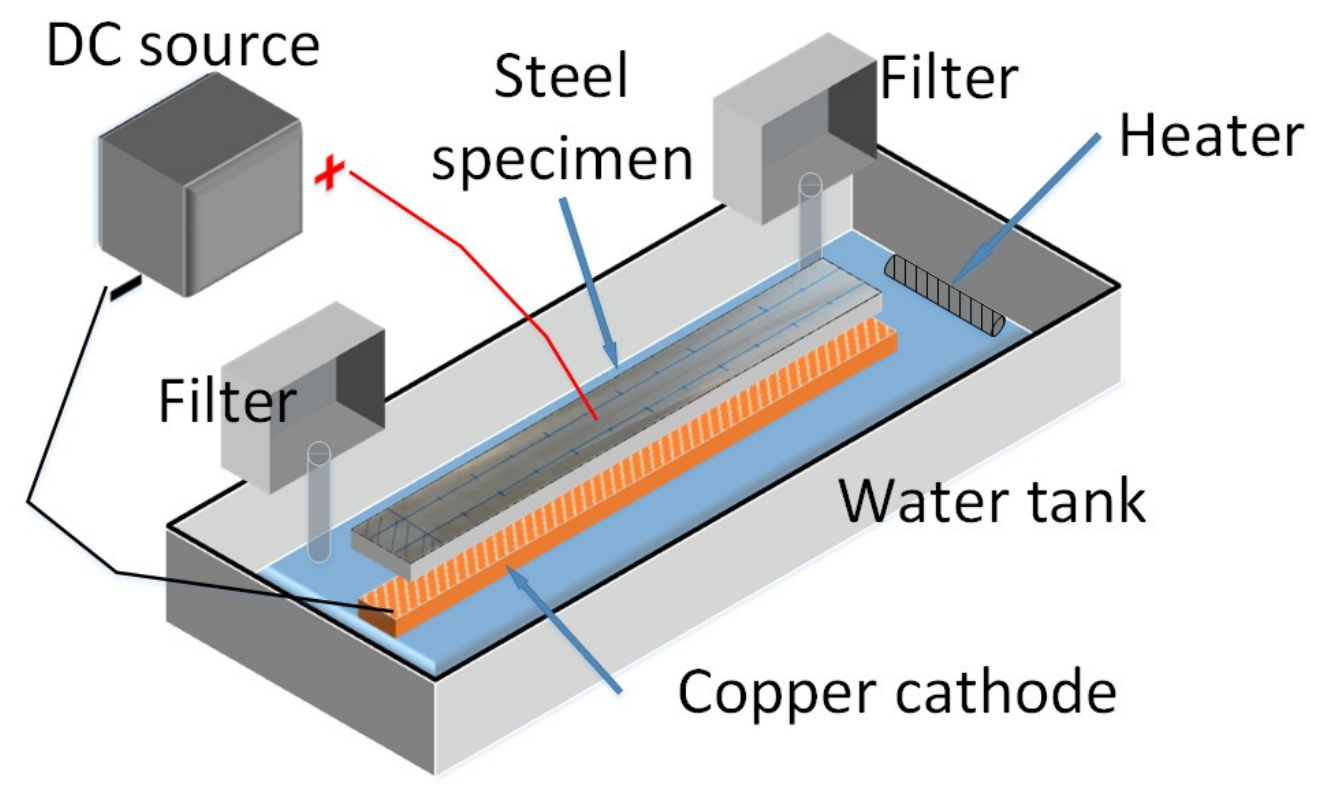

Fig. 1. Accelerated corrosion setup impressing DC current on steel plate specimen in $\mathrm{NaCl}$ solution, with steel specimen, copper cathode connected to DC source, water tank with filters and heater. 


\section{EXPERIMENTS}

Two plate specimens $(650 \mathrm{~mm} \times 100 \mathrm{~mm})$ were cut from a single piece of mild steel (EN3B - AISI 1020) and then milled to $11 \mathrm{~mm}$ thickness. The used material has very similar mechanical properties to that of steel used in shipbuilding (Poisson's ratio 0.303 , yield strength $295 \mathrm{MPa}$, tensile strength $395 \mathrm{MPa}$ ). One specimen was milled down in approximately $0.2 \mathrm{~mm}$ steps to a final thickness of $9.43 \mathrm{~mm}$ to achieve a uniform thickness reduction. The other specimen was subjected to accelerated corrosion using the reverse of impressed current cathodic protection [19, 2]. The setup consisted of a DC voltage source, the steel plate partially submerged as the anode in $\mathrm{NaCl}$ solution (salt water), suspended above the copper cathode (Fig. 1). The DC voltage source supplied a current of approximately 5A at $6 \mathrm{~V}$. The thickness was monitored using longitudinal pulse-echo ultrasonic measurements at $5 \mathrm{MHz}$ along the center line of the plate. The accelerated corrosion was interrupted about every 30 hours to perform a guided ultrasonic wave measurement for thickness reductions matching approximately the $0.2 \mathrm{~mm}$ milling steps. The average thickness was in general close to the required thickness and reduced from $11.0 \mathrm{~mm}$ to $9.42 \mathrm{~mm}$. Some fluctuations in the achieved corrosion rate occurred due to changes in the temperature and to the amounts of products of the reaction, iron hydroxide, causing varying conductivity of the solution. Two filters and a heater were attached to the water bath to remove some of the corrosion product and to achieve a faster and more consistent corrosion rate.

The high frequency guided ultrasonic waves were generated at the plate surface using a standard Rayleigh angle beam transducer with a center frequency of $0.5 \mathrm{MHz}$. The wave propagation investigation was performed using a 10-cycle tone burst excitation (sinusoid in a Hanning window), generated in a programmable function generator and amplified using a broadband power amplifier. A heterodyne laser interferometer was used for point measurements of the out-of-plane displacement field along the propagation of the ultrasonic pulse [20], as displayed in Fig. 2. The interferometer head was moved parallel to the plate surface by means of a positioning system with a step size of $1 \mathrm{~mm}$ for a distance of $450 \mathrm{~mm}$ from the transducer location. The signal was filtered using a band pass filter, averaged (50 averages) and recorded using a digital storage oscilloscope. Using Matlab the amplitude at $0.45 \mathrm{MHz}$ was extracted using Fast Fourier Transform (FFT) for each measurement location.

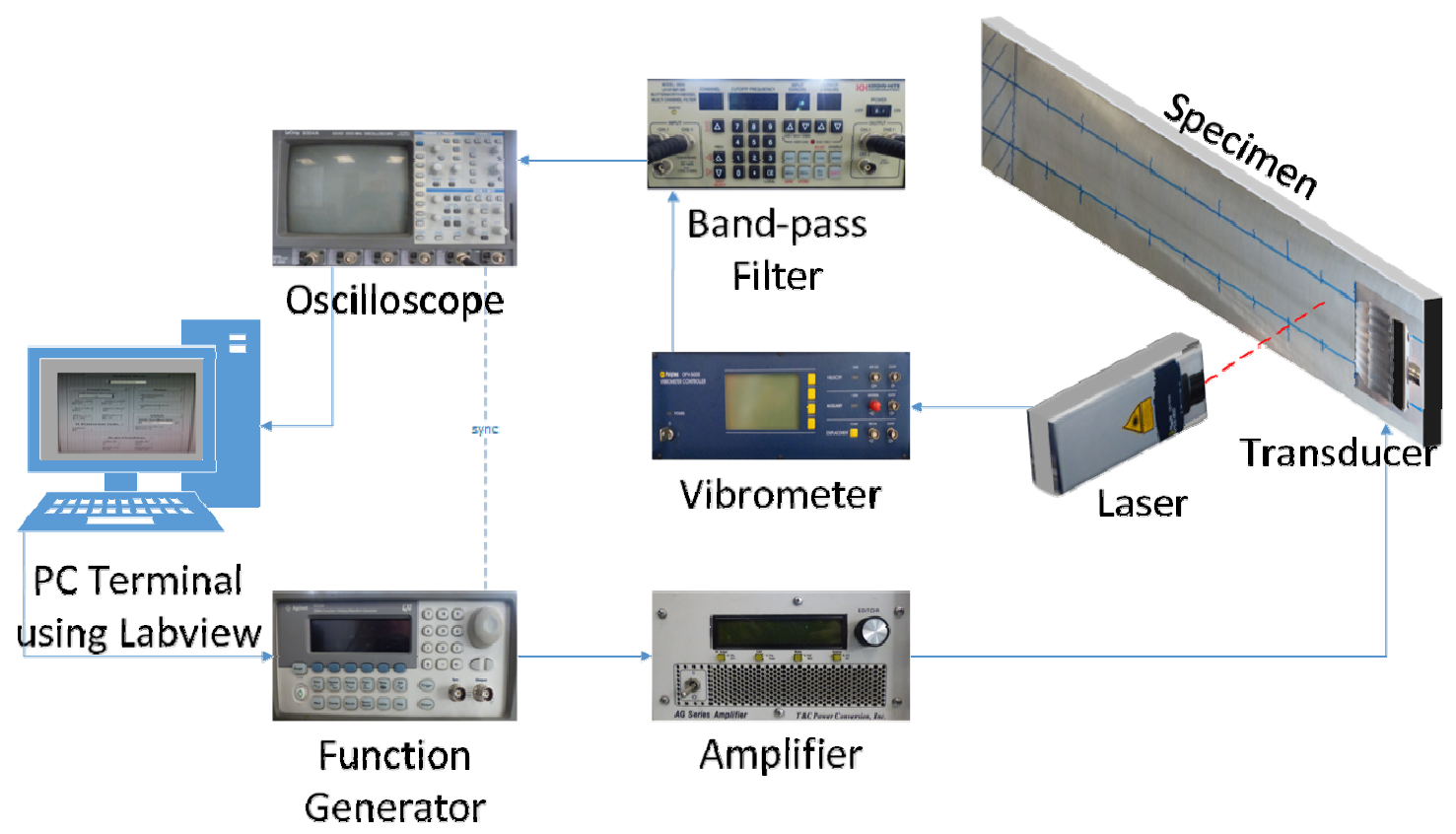

Fig. 2. Experimental setup for laser measurement of high frequency guided ultrasonic wave propagation on steel specimen. 


\section{GUIDED WAVE PROPAGATION FOR UNIFORM THICKNESS REDUCTION}

The first plate specimen was milled in $0.2 \mathrm{~mm}$ steps from a uniform thickness of $11.0 \mathrm{~mm}(+/-0.01 \mathrm{~mm})$ to a thickness of $9.43 \mathrm{~mm}$. For each of the nine available plate thicknesses the guided ultrasonic wave propagation along the center line of the specimen was measured and the amplitude at $0.45 \mathrm{MHz}$ (FFT) versus propagation distance curve analyzed. The amplitude variation due to the beating effect between the two fundamental Lamb wave modes can be clearly observed in Fig. 3. The amplitude decreases as the wave propagates from the excitation location and then periodically increases and decreases again. It has to be noted that this effect depends strongly on the frequency-thickness product, so that in the time domain the amplitude reduction is less pronounced as the wave pulse contains energy over a range of frequencies. The measurement curves do not go to zero amplitude and show some variation over shorter length scale due to an interference with higher wave modes and slightly different effective excitation amplitudes for the $\mathrm{A}_{0}$ and $\mathrm{S}_{0}$ modes [21]. The measured amplitude curves were fitted using Matlab with the theoretically predicted exponentially decreasing cosine curve and good agreement for the principal features can be seen in Fig. 3 for the measurements at different plate thicknesses. The experimental beatlength matched well with the theoretically predicted beatlength using Disperse [22] with maximum error of less than $8 \%$ for all cases (table 1 ).

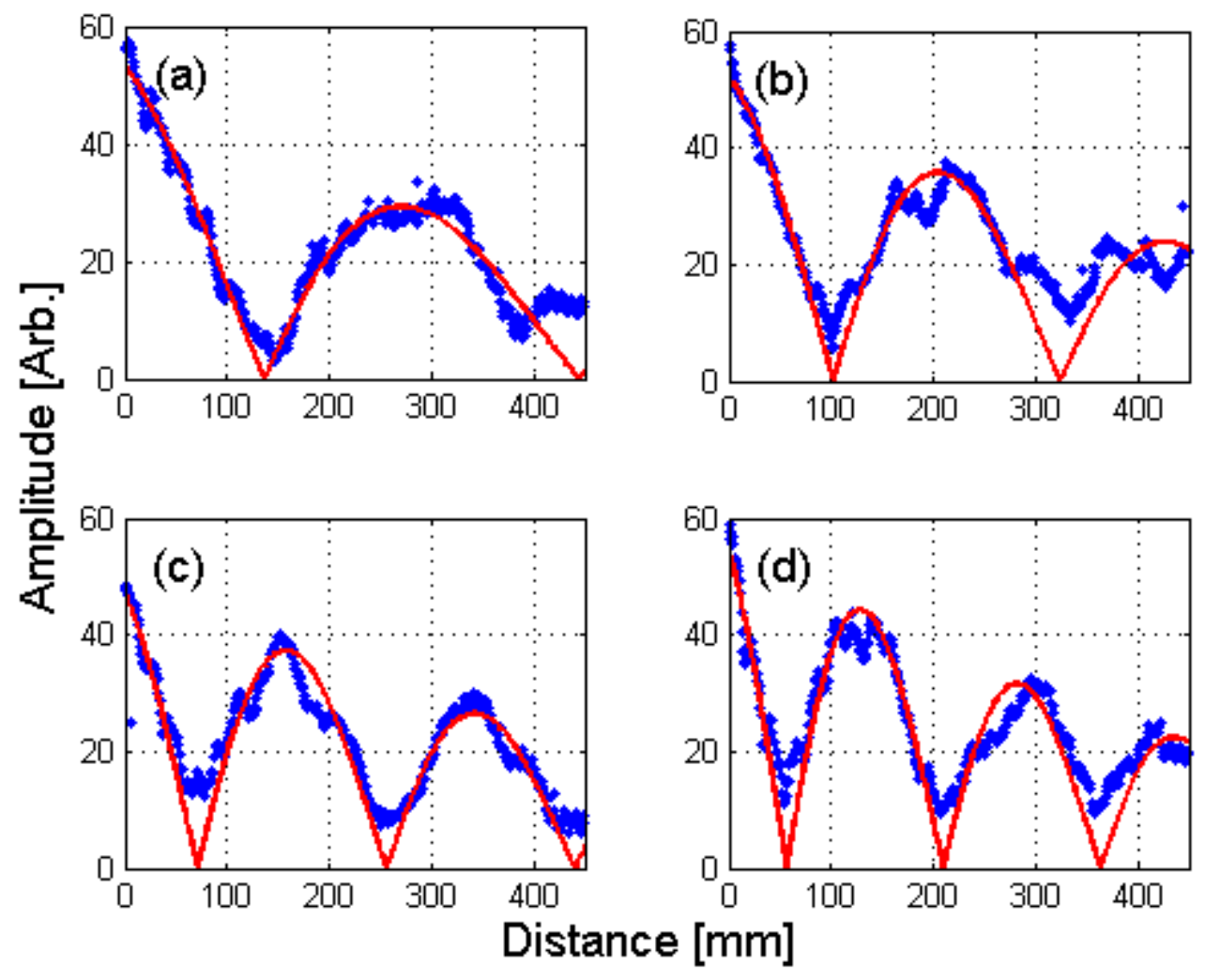

Fig. 3. Measured amplitude of high frequency guided wave at $0.45 \mathrm{MHz}$ (FFT) along milled steel specimen, measured using laser interferometer: (a) $11.00 \mathrm{~mm}$; (b) $10.39 \mathrm{~mm}$; (c) $9.80 \mathrm{~mm}$, (d) $9.43 \mathrm{~mm}$ thickness; measured amplitude: blue dots; exponential fit: red solid line. 
Table 1. Theoretical and experimentally measured beatlength on milled steel plate specimen.

\begin{tabular}{|c|c|c|c|}
\hline $\begin{array}{c}\text { Thickness } \\
{[\mathbf{m m}]}\end{array}$ & $\begin{array}{c}\text { Theoretical } \\
\text { Beatlength } \\
{[\mathbf{m m}]}\end{array}$ & $\begin{array}{c}\text { Experimental } \\
\text { Beatlength } \\
{[\mathbf{m m}]}\end{array}$ & Error \\
\hline 11.00 & 287.5 & 307.2 & $6.85 \%$ \\
\hline 10.84 & 270.2 & 290.9 & $7.66 \%$ \\
\hline 10.64 & 249.8 & 252.9 & $1.24 \%$ \\
\hline 10.39 & 226.1 & 222.2 & $-1.72 \%$ \\
\hline 10.14 & 204.7 & 198 & $-3.27 \%$ \\
\hline 10.01 & 194.3 & 195.1 & $0.41 \%$ \\
\hline 9.80 & 178.4 & 184.6 & $3.48 \%$ \\
\hline 9.58 & 163 & 165.4 & $1.47 \%$ \\
\hline 9.43 & 153.2 & 153.5 & $0.20 \%$ \\
\hline
\end{tabular}

\section{GUIDED WAVE PROPAGATION FOR CORRODED SPECIMEN}

The accelerated corrosion of the second plate specimen was interrupted regularly at intervals of about 30 hours. For each plate thickness the guided ultrasonic wave propagation along the center line of the specimen was measured. The amplitude versus propagation distance curve was analyzed and compared to the closest matching curve obtained for the milled specimen. Similar behavior with periodic amplitude and decrease due to the wave interference can be seen in Fig. 4. The experimental amplitude variation for the corroded plate specimen is similar to the one obtained for the milled specimen. The fit of the exponentially decreasing cosine curve matches the amplitude measurements on the corroded plate quite well, and the decrease in beatlength with decreasing thickness can be clearly observed. The maximum error between theoretical and experimental beatlength is slightly larger than for the uniform (milled) thickness reduction, with a maximum error of about $10 \%$ (table 2). This slightly reduces the sensitivity for the determination of the plate thickness reduction, but would be sufficient to detect generalized corrosion before it affects the structural integrity.

Shown in Fig. 5 is the experimentally obtained beatlength at $0.45 \mathrm{MHz}$ for the milled and corroded specimens against the actually measured plate thickness. Reasonably good agreement with the theoretically predicted beatlength can be observed with the decrease in beatlength with specimen thickness. For the thicker specimens the maximum laser measurement length was comparable with the beatlength, resulting in a larger error in the value obtained from the fitting procedure. This error decreased with reduced beatlength and overall a good match and significant change in beatlength can be observed.

For the maximum change in thickness of about $1.6 \mathrm{~mm}(14 \%)$ the beatlength changed by approximately $46 \%$ for both the milled and corroded specimen. The method is sensitive enough to allow a determination of the plate thickness reduction with a resolution of about $0.2 \mathrm{~mm}$ ( $2 \%$ of plate thickness), which would be more than sufficient to detect generalized corrosion before it affects the structural integrity of a ship hull or offshore installation. 
Table 2. Theoretical and experimentally measured beatlength for corroded steel plate specimen.

\begin{tabular}{|c|c|c|c|}
\hline $\begin{array}{c}\text { Measured } \\
\text { Thickness } \\
{[\mathbf{m m}]}\end{array}$ & $\begin{array}{c}\text { Theoretical } \\
\text { Beatlength } \\
{[\mathbf{m m}]}\end{array}$ & $\begin{array}{c}\text { Experimental } \\
\text { Beatlength } \\
{[\mathbf{m m}]}\end{array}$ & Error \\
\hline 10.80 & 265.9 & 274.5 & $3.23 \%$ \\
\hline 10.67 & 252.7 & 270.6 & $7.08 \%$ \\
\hline 10.49 & 235.3 & 259.3 & $10.20 \%$ \\
\hline 10.30 & 218.3 & 216.1 & $-1.01 \%$ \\
\hline 9.82 & 179.8 & 183.8 & $2.22 \%$ \\
\hline 9.60 & 164.3 & 168.1 & $2.31 \%$ \\
\hline 9.42 & 152.6 & 162.3 & $6.36 \%$ \\
\hline
\end{tabular}

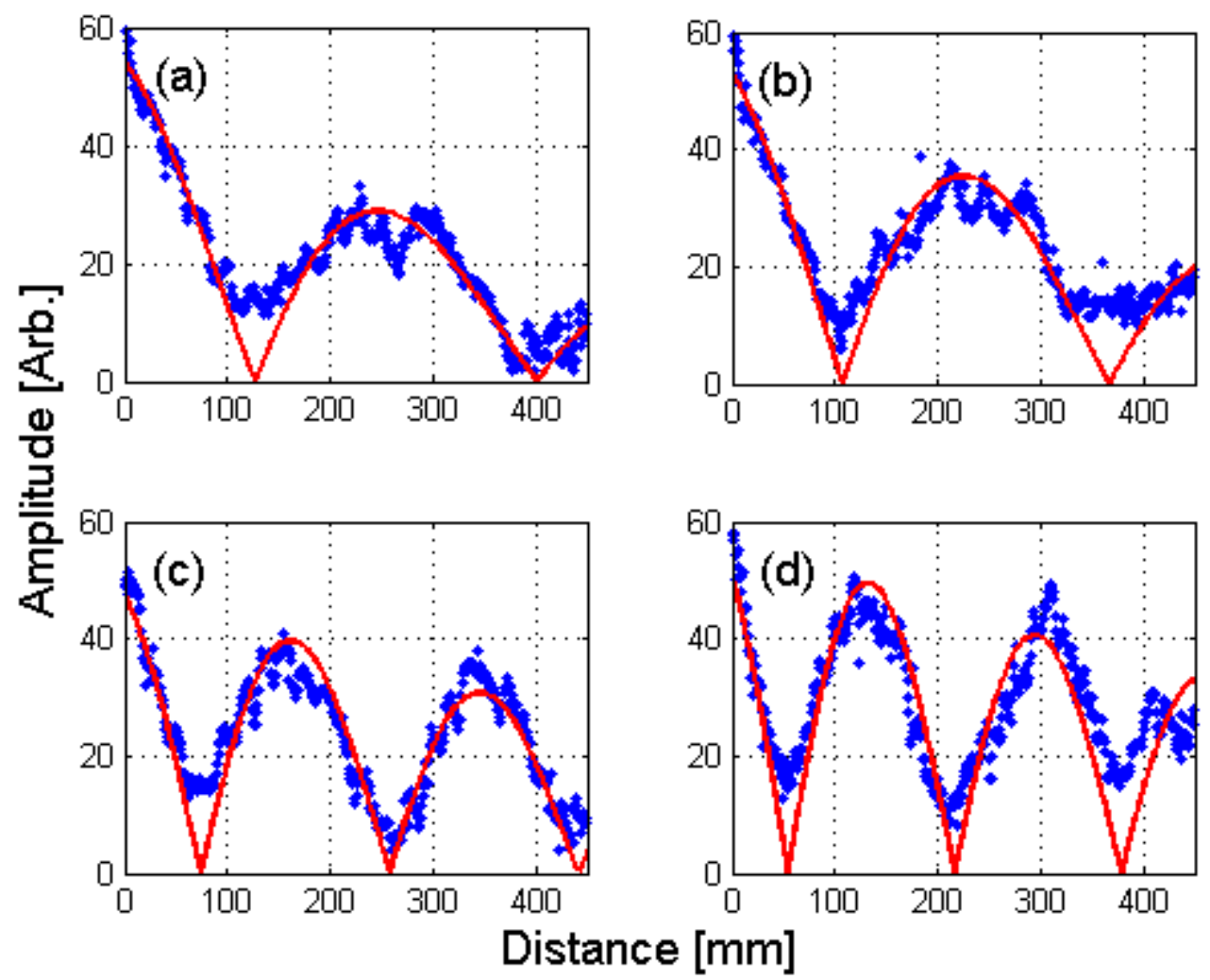

Fig. 4. Measured amplitude of high frequency guided wave at $0.45 \mathrm{MHz}$ (FFT) along corroded steel specimen, measured using laser interferometer: a) $10.80 \mathrm{~mm}$; b) $10.49 \mathrm{~mm}$, c) $9.82 \mathrm{~mm}$, d) $9.42 \mathrm{~mm}$ approximate thickness; measured amplitude: blue dots; exponential fit: red solid line. 


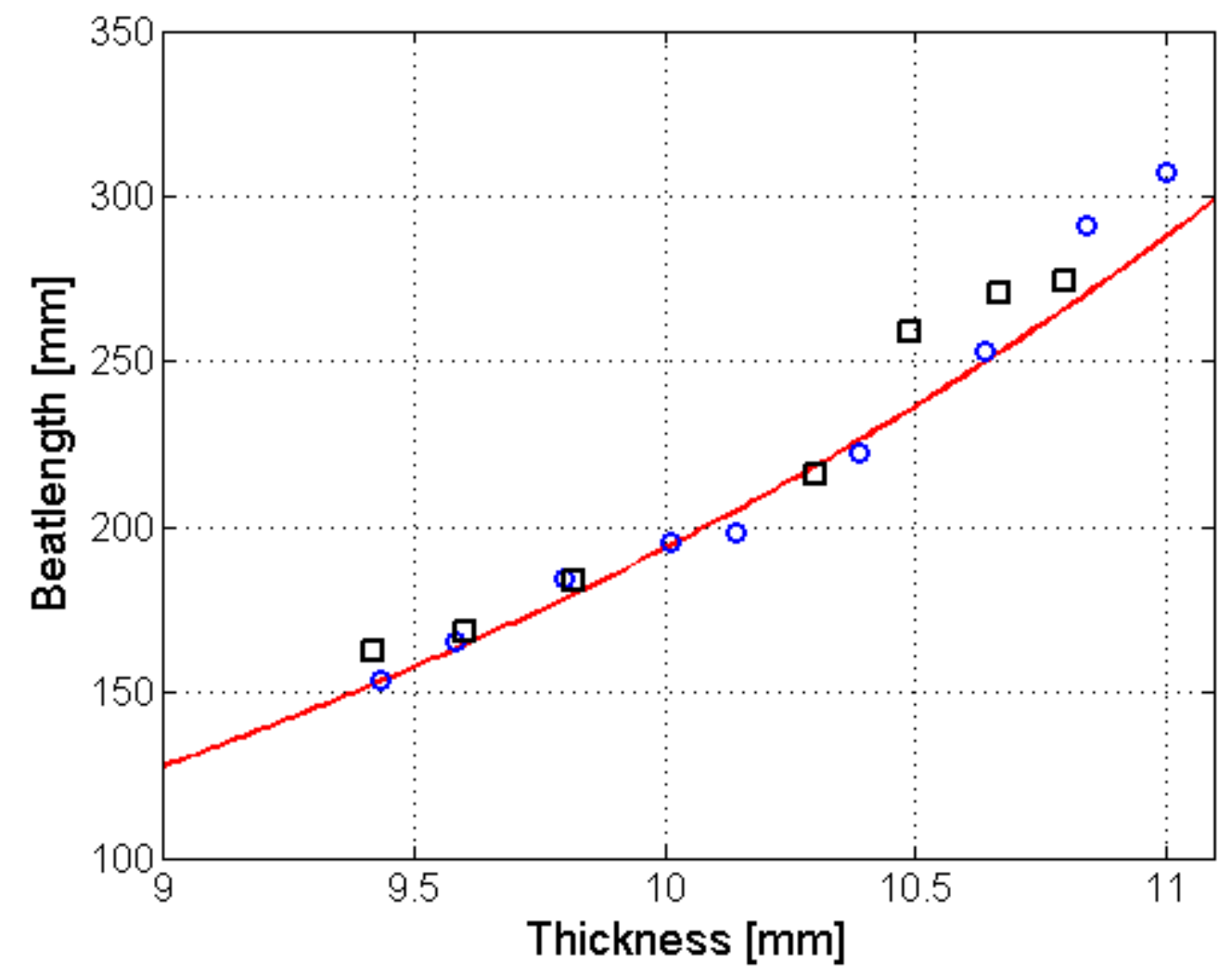

Fig. 5. Comparison of theoretically predicted beatlength (solid, red line) against measured beatlength (fit from laser amplitude measurements at $0.45 \mathrm{MHz}$ ): milled specimen: blue circles; corroded specimen: black squares.

\section{CONCLUSIONS}

This contribution investigated the monitoring of wall thickness reduction using high frequency guided ultrasonic waves propagating along the structure and allowing for the measurement over a reasonable propagation length as compared to through-thickness point measurements. The required high frequency guided wave modes were excited using standard wedge transducers and measured using a laser interferometer. The length scale of the amplitude beatlength due to the interference of the wave modes was quantified from a fit of the experimentally measured amplitude curves along the propagation distance. Uniform plate thickness reduction was achieved by milling the plate specimen to the required thicknesses and good agreement of the measured beatlength with theoretical predictions was achieved, demonstrating the sensitivity of the proposed methodology. Wall thickness loss due to accelerated corrosion resulted in a comparable reduction of beatlength and could be measured with similar precision. The achieved sensitivity would be sufficient to detect generalized corrosion before it affects the structural integrity, e.g., of ship hull plates. The measurement methodology will be further developed using standard wedge transducers to allow for point measurement and evaluation of the beatlength and thus plate thickness reduction, allowing for the fast measurement in an industrial environment. Further investigations will explore the sensitivity of the high frequency guided ultrasonic waves to typical pitting corrosion.

\section{ACKNOWLEDGEMENTS}

The authors would like to thank Jason Sanderson and Adrian Safciuc for their contribution to the development of the guided ultrasonic wave and corrosion measurement procedures and the UCL Mechanical Engineering workshop for the precision machining. 


\section{REFERENCES}

[1] Nakai, T., Matsushita, H., Yamamoto, N. and Arai, H., "Effect of pitting corrosion on local strength of hold frames of bulk carriers (1st report)," Marine Struct. 17, 403-432 (2004).

[2] Fromme, P., "Monitoring of corrosion damage using high-frequency guided ultrasonic waves," Proceedings of SPIE 8695,869502 (2013).

[3] Rose, J. L., "Standing on the shoulders of giants: An example of guided wave inspection," Mat. Eval. 60, 53-59 (2002).

[4] Fromme, P., "Monitoring of Plate Structures Using Guided Ultrasonic Waves," in Rev. Prog. QNDE 27, ed. by D.O. Thompson and D.E. Chimenti, AIP Conference Proceedings 975, New York, 78-85 (2008).

[5] Fromme, P., Wilcox, P.D., Lowe, M., and Cawley, P., "On the Scattering and Mode Conversion of the A0 Lamb Wave Mode at Circular Defects in Plates," in Rev. Prog. QNDE 23, ed. by D.O. Thompson and D.E. Chimenti, AIP Conference Proceedings 700, New York, 142-149 (2004).

[6] Masserey, B. and Fromme, P., "In-situ Monitoring of Fatigue Crack Growth at Fastener Holes Using Rayleigh-like Waves," in Rev. Prog. QNDE 27, ed. by D.O. Thompson and D.E. Chimenti, AIP Conference Proceedings 975, New York, 1484-1491 (2008).

[7] Fromme, P., Wilcox, P. D., Lowe, M. J. S. and Cawley, P., "On the development and testing of a guided ultrasonic wave array for structural integrity monitoring," IEEE Trans. Ultrason. Ferroelectr. Freq. Control 53, 777-785 (2006).

[8] Fromme, P., "Health Monitoring of Plate Structures using Guided Waves," Proceedings of SPIE 6935, 69350W (2008).

[9] Alleyne, D. N. and Cawley, P., "The interaction of Lamb waves with defects," IEEE Trans. Ultrason. Ferroelectr. Freq. Control 39, 381-397 (1992).

[10] Masserey, B. and Fromme, P., "Fatigue Crack Growth Monitoring using High Frequency Guided Waves," Struct. Health Monit. 12, 484-493 (2013).

[11] Terrien, N., Osmont, D., Royer, D., Lepoutre, F. and Déom, A., "A combined finite element and modal decomposition method to study the interaction of Lamb modes with micro-defects," Ultrasonics 46, 47-78 (2007).

[12] Greve, D. W., Zheng P. and Oppenheim I. J., "The transition from Lamb waves to longitudinal waves in plates," Smart Mater. Struct. 17, 035029 (2008).

[13] Masserey, B. and Fromme, P., "On the reflection of coupled Rayleigh-like waves at surface defects in plates," J. Acoust. Soc. Am. 123, 88-98 (2008).

[14] Viktorov, I. A., [Rayleigh and Lamb Waves], Plenum Press, New York, 93-96 (1967).

[15] Masserey, B. and Fromme, P., "Surface defect detection in stiffened plate structures using Rayleigh-like wave," NDT \& E Int. 42, 564-572 (2009).

[16] Masserey, B. and Fromme, P., "In-situ Monitoring of Fatigue Crack Growth at Fastener Holes Using Rayleigh-like Waves" in Rev. Prog. QNDE 27, ed. by D.O. Thompson and D.E. Chimenti, AIP Conference Proceedings 975, New York, pp. 1484-1491 (2008).

[17] Ti, B. W., O’Brien, W. D. and Harris, J. G., "Measurements of coupled Rayleigh wave propagation in an elastic plate," J. Acoust. Soc. Am. 102, 1528-1531 (1997).

[18] Auld, B.A., [Acoustic Fields and Waves in Solids], Wiley, New York, Vol. 2, 93-94 (1973).

[19] Cegla, F., Cawley, P., Allin, J. and Davies, J., "High-Temperature $\left(>500^{\circ} \mathrm{C}\right)$ Wall Thickness Monitoring Using DryCoupled Ultrasonic Waveguide Transducers," IEEE Trans. Ultrason. Ferroelectr. Freq. Control 58, 156-167 (2011).

[20] Fromme, P. and Sayir, M. B., "Detection of cracks at rivet holes using guided waves," Ultrasonics 40, 199-203 (2002).

[21] Masserey, B. and Fromme, P., "High-frequency guided waves for defect detection in stiffened plate structures," Insight 51, 667-671 (2009).

[22] Pavlakovic, B., Lowe, M. J. S., Alleyne, D. and Cawley, P., "Disperse: A general purpose program for creating dispersion curves," Proc. QNDE 16, 185-192 (1997). 